\title{
EDITORIAL
}

\section{Journal name change}

Jamie Trapp ${ }^{1}$

Published online: 10 July 2019

(c) Australasian College of Physical Scientists and Engineers in Medicine 2019

From 2020 (Volume 43) Australasian Physical \& Engineering Sciences in Medicine will undergo a name change to Physical and Engineering Sciences in Medicine.

The name change involves removing Australasian from the title, as well as changing $\&$ to and. The second change is obviously minor and the purpose is to limit confusion and incorrect citations, and would not have occurred if not for the first change.

The removal of Australasian from the title occurs for several reasons, but essentially it reflects that the journal has evolved from being a local medical physics journal, as outlined in Kenneth Clarke's editorial [1], into an international multidisciplinary journal for both physics and engineering in medicine.
The journal will retain its very broad scope and accept and publish manuscripts covering a broad range of topics which highlight physics and engineering in medicine.

\section{Reference}

1. Clarke K (2007) An historical perspective of the APESM. Australas Phys Eng Sci Med 30:xiv

Publisher's Note Springer Nature remains neutral with regard to jurisdictional claims in published maps and institutional affiliations.
Jamie Trapp

j.trapp@qut.edu.au

1 School of Chemistry, Physics, and Mechanical Engineering, Queensland University of Technology, Brisbane, Australia 